\title{
AC 2008-900: UNDERSTANDING THE EFFECT OF RESIDUAL STRESSES ON SURFACE INTEGRITY AND HOW TO MEASURE THEM BY A NON-DESTRUCTIVE METHOD
}

\author{
Daniel Magda, Weber State University
}




\title{
Understanding the Effect of Residual Stresses on Surface Integrity and how to Measure them by a Non-Destructive Method
}

\begin{abstract}
In teaching the theory of solid mechanics of metallic materials there are basically two kinds of stresses that a component can be subjected to. The first are the applied stresses generated from a loading condition that the component experiences in service. This load can be either a static or dynamic where the stresses are easily determined by traditional strength of materials equations, continuum mechanics or by finite element analysis. The second type of mechanical stress that occurs in materials is classified as residual stresses. These are the stresses that remain in the material after all the applied loads are removed.
\end{abstract}

Mechanical engineering and engineering technology students have a difficult time understanding the generation of residual stresses, measuring them and their overall effect on design life. Residual stresses typically come from non-uniform plastic flow due to some previous loading or manufacturing process. Some of these processes are but not limited to casting, machining, welding, grinding, shot peening, quenching, nonuniform cold working such as twisting, bending, forging and drawing.

Engineering students must learn that residual stresses will have an effect on the surface integrity. However, the literature shows that depending on the magnitude and direction that these stresses hold they may be harmful or beneficial to the overall design life. Applied stresses and residual stresses add algebraically, as long as their sum does not exceed the elastic limit of the material. Compressive residual stresses prolong fatigue life while tensile residual stresses will cause premature brittle failure. It is important to teach that residual stresses must form an equilibrium system within the component. This means that tensile residual stress in a part must be balanced by compressive residual stresses in another.

There are two teaching methods for measuring residual stresses. The first is the mechanical relaxation dissection method which is very time consuming and inherently destructive. This method utilizes strain gauges to measure the strain relaxation after the part is sectioned away from the main body. The second method that is taught in this paper is the technique of residual stress measurement by $\mathrm{x}$-ray diffraction. This method depends on the fact that the spacing $\mathrm{d}$ of the atomic (hkl) planes in a metal material is altered by stress and that $\mathrm{d}$ can be determined by measuring the angular position of a diffracted $\mathrm{x}$-ray beam. The fractional change in $\mathrm{d}$ is the strain from which the stress can be calculated.

\section{Introduction}

This paper addresses the use of $\mathrm{x}$-ray diffraction as a nondestructive method for the measurement of macroscopic residual stress. The paper also reviews the published literature to incorporate into the classroom empirical research on the effect of residual stresses have on surface integrity. These findings will facilitate lecture material that are not published in traditional textbooks relating to strength of materials and design life. Although stress is an extrinsic property, it 
cannot be directly measured. Values of force and area are measured first and then the stress can be calculated. In x-ray diffraction the strain is measured by the spacing change of atomic (hkl) planes. This spacing change $\mathrm{d}$ from an unstressed state is determined by the Bragg equation $n \lambda=2 \mathrm{~d} \sin \theta$. Any additional change in the lattice spacing will result in shifting the Bragg diffraction angle $2 \theta$. This diffraction of a monochromatic beam has good precision when diffraction angles $2 \theta$ are greater than $120^{\circ}$. With the theory of elasticity the stress can be calculated with the use of Poisson's ratio and the modulus of elasticity.

X-ray diffraction stress measurement has an advantage over mechanical methods. Typical mechanical methods are destructive to the part. Therefore, measurements cannot be repeated for statistical significance. Also, microstresses cannot be measured by mechanical methods. Macrostresses are stresses that range over a greater distance than the grain of the material. Theses residual macrostresses will have a tremendous influence on surface integrity and failure analysis. By measuring three different directions of stress on the specimen surface and assumeing a plane stress condition, the principal stresses along with their directions can be calculated by implementing Mohr's circle.

An overview of this paper teaches the theory and background needed to understand the formation of residual stresses and its measurement by x-ray diffraction. In particular it focuses on the formation of residual stresses caused by machining and manufacturing processes. However, this paper can also be utilized as supplementary lecture material in the classroom. Some current engineering courses for this material integration would be Failure Analysis, Experimental Stress Analysis, Principles of Non-Destructive evaluation (lab class) and Directed Readings. The paper is written to facilitate the learning process on the influence of residual stresses affecting the surface integrity and design life of materials. With these topics addressed in this paper the students should have background knowledge in calculus, material science and solid mechanics.

\section{Generation of Surface Residual Stresses from Cutting}

When metal is being cut by a cutting tool, the surface layer undergoes heavy distortion. The cutting process is accompanied by heating of the chip and the tool and also the material under the cutting edge. This combination of heat and distortion leads to a state of stress that is a maximum at the surface of the material ${ }^{1}$. The value of stress is different in the various directions relative to the direction of travel of the tool, and has its maximum in a direction parallel to the tool movement. Most of the residual stress is generated from the mechanical action of the tool and not from the thermal effect of the cutting process. The effect of heating in the material by cutting would be expected to be approximately equal in all directions which is not the case with the mechanical effect. Figures 1 and 2 show the distortion of the material being cut by a single point cutting tool. The grains near the surface are pulled out parallel to the surface and look like a layer of thin strings. Further down into the material the grains take on a spherical shape with their upper ends bending parallel with the surface. The grain of the metal situated in the path of the cutting edge is captured by the tool, and the projecting part of the grain is being carried away in the chip while still in connection with the remaining part of the grain. The middle section of the grain is pulled out to a thin string and is finally torn off. Part of the grain is carried off by the chip while the remaining part adheres to the work surface. The top part of the portion remaining 


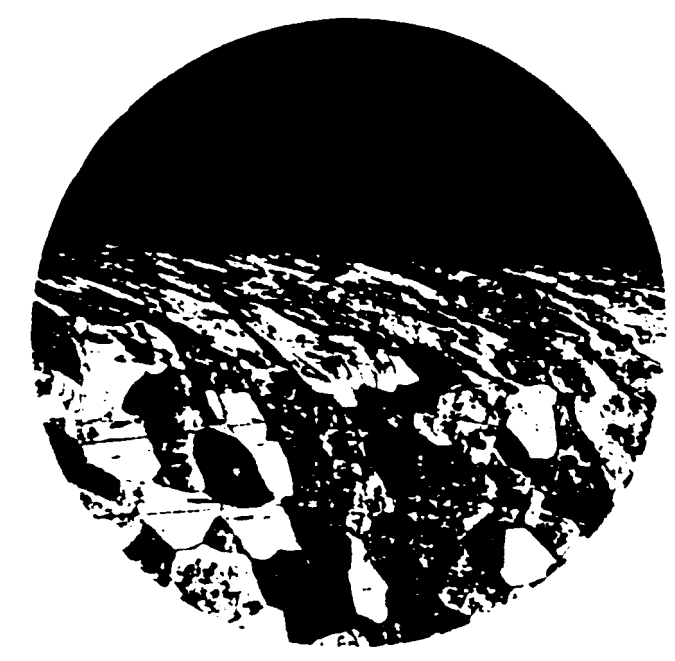

Figure 1. Micrograph of grains showing the distortion of plastically deforming the surface.

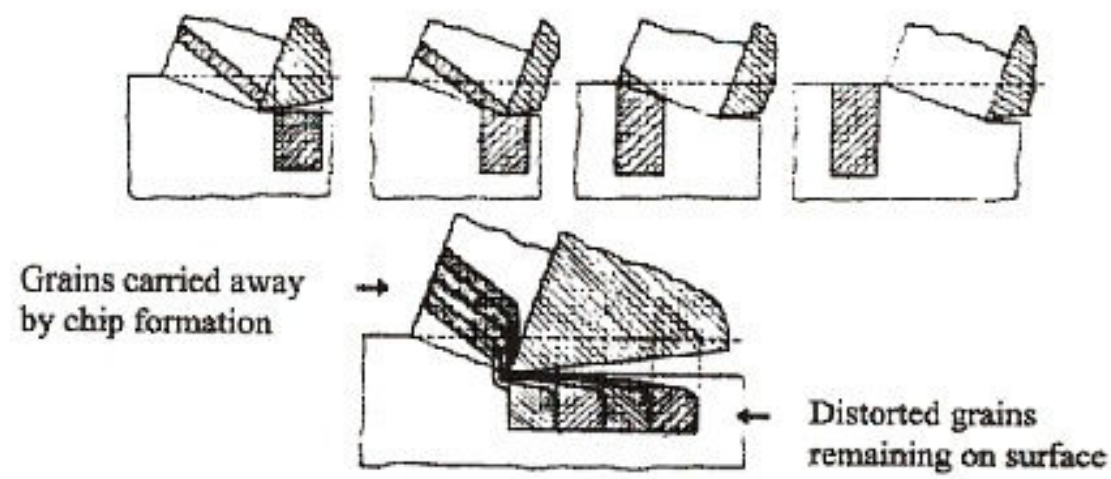

Figure 2. Diacammatic views of chip formation material under a machined surface.

in the surface has been subjected to a pull while still in connection with the rest of the material. This pull has given effect not only to the distortion, but also to a tensile stress. When the grains are relieved from the pull, the strained part will try to contract, but is prevented from this by the underlying material. Then, the grains must retain their tension. The results from this cutting process produce a residual stress within the surface of the material.

\section{Residual Stress From Plastic Deformation}

Residual stresses generated by cutting are complex. It is difficult to determine the direction and magnitude of the stress in the underlying surface. A simple way of understanding residual stress is in terms of the moment-curvature relation of a rectangular bar in pure bending ${ }^{2}$. A straight bar 
in Figure 3 is bent around a circular rod of radius $R_{0}$. When the bar is released the radius of curvature increases to $R_{1}$ and there is a residual stress which remains in the bar. The moment curvature relation for the complete cycle of loading and unloading of the rectangular bar is shown in Figure 4. This curve represents the material behavior to be elastic then changing to be perfectly plastic after yielding takes place. The stress distribution when the bar has the curvature $1 / R_{o}$ is shown in Figure 5a. This is defined as the limit moment or the fully plastic moment. The bending moment magnitude corresponding to this stress distribution is $\mathrm{M}_{\mathrm{b}}=\mathrm{M}_{\mathrm{L}}=$ $3 / 2 \mathrm{M}_{\mathrm{y}}$. The elastic stress distribution shown in Figure $5 \mathrm{~b}$ has as its resultant bending movement of magnitude $\mathrm{M}_{\mathrm{b}}=-3 / 2 \mathrm{M}_{\mathrm{y}}$. There will be a net bending moment corresponding to the released condition in Figure 3. The residual stress distribution then existing in the bar is shown in Figure 5c. Above the neutral surface the stress varies linearly from $-\mathrm{Y}$ at the center to $+\mathrm{Y} / 2$ at the inner radius of the bar.
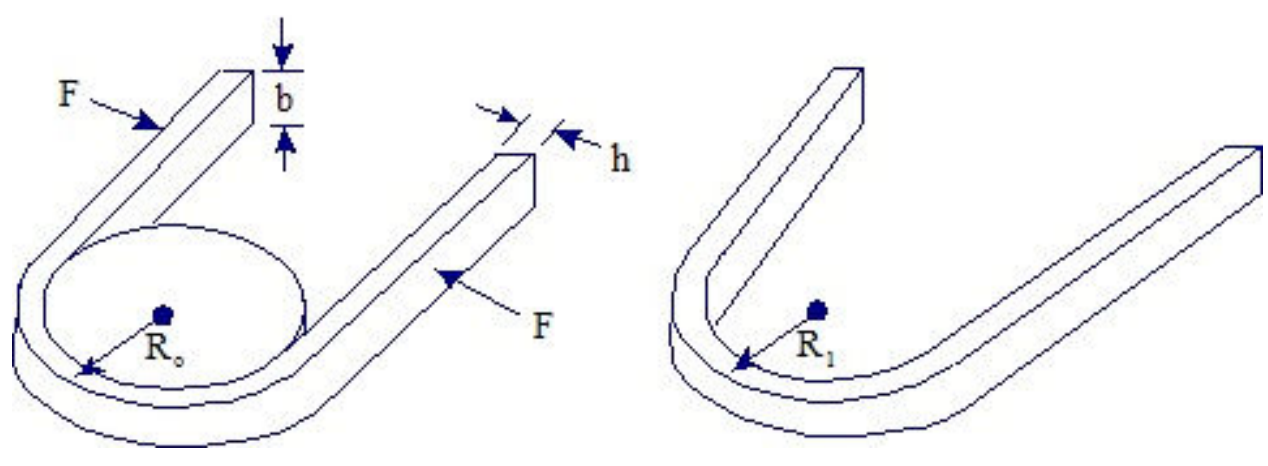

Figure 3. Elastic springback from plastic bending of a rectangular bar.

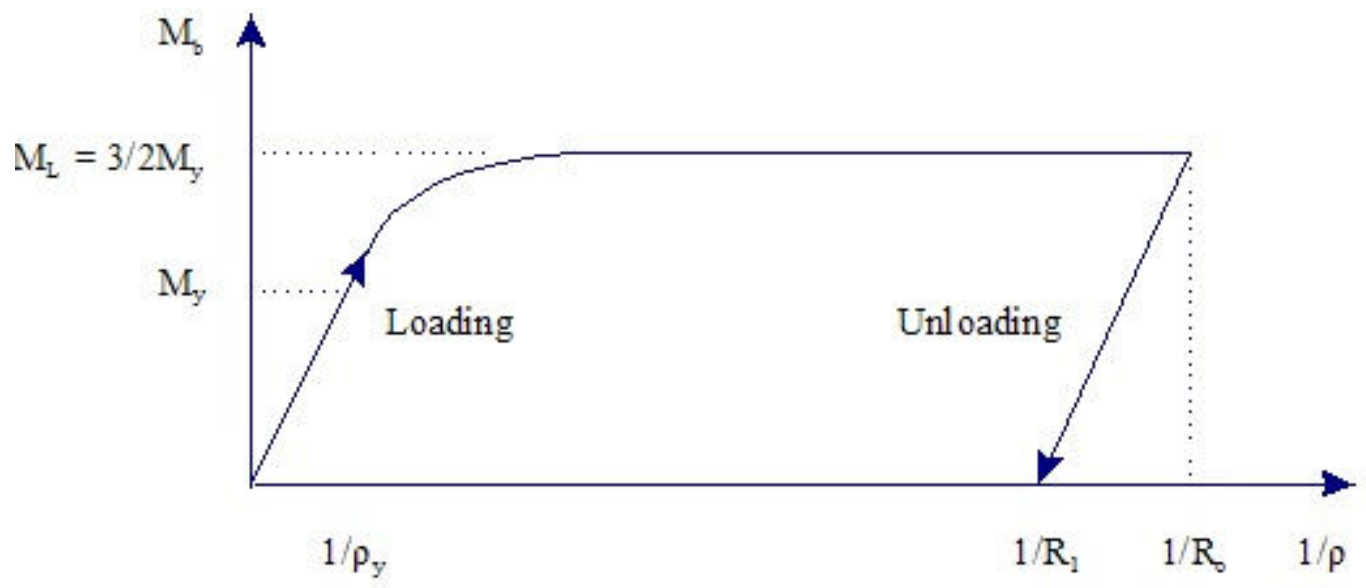

Figure 4. Moment curvature relation for Figure 3 of one cycle of loading and unloading. 


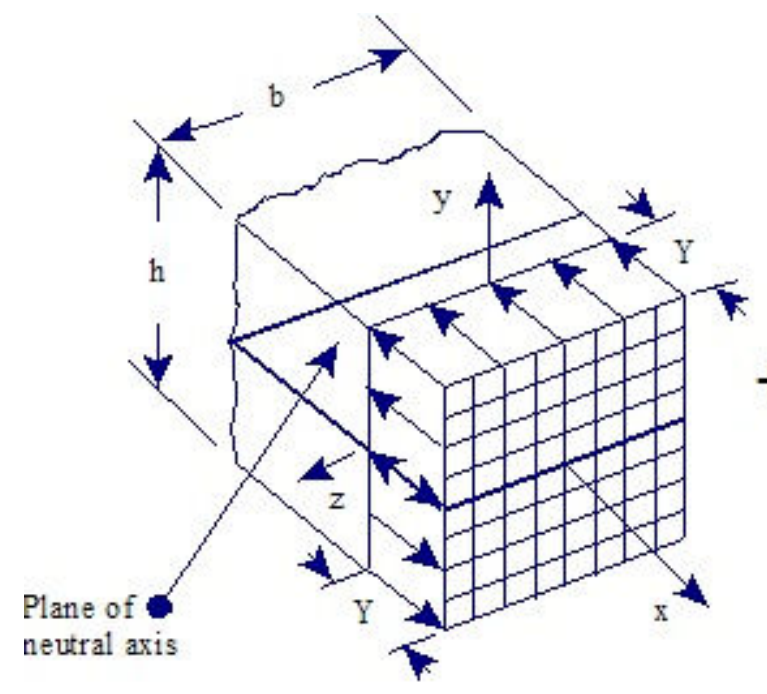

(a)

$$
\begin{aligned}
& \mathrm{M}_{\mathrm{b}}=\mathrm{M}_{\mathrm{L}}=3 / 2 \mathrm{M}_{\mathrm{y}} \\
& 1 / \rho=1 / \mathrm{R}_{\mathrm{o}}
\end{aligned}
$$

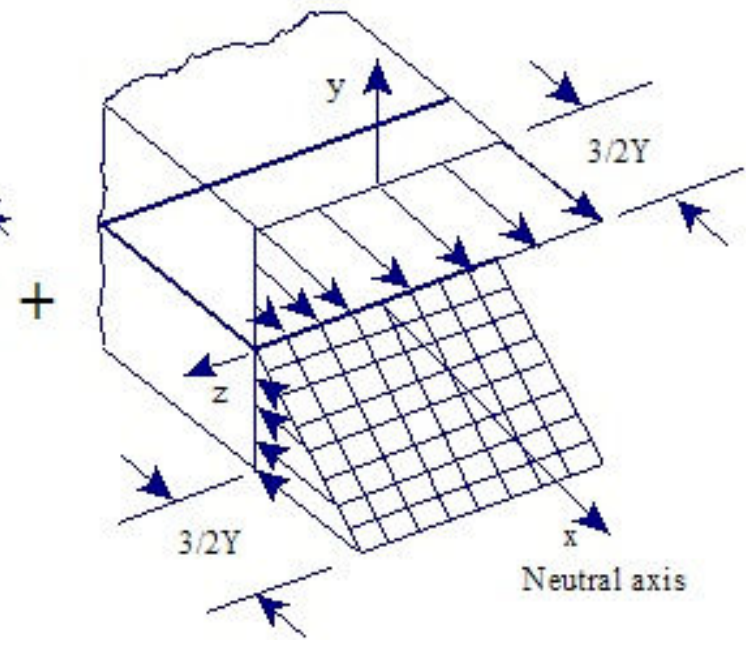

(b) $\mathrm{M}_{\mathrm{b}}=\mathrm{M}_{\mathrm{L}}=-3 / 2 \mathrm{M}_{\mathrm{y}}$ $\Delta 1 / \mathrm{R}_{\mathrm{o}}=3 / 2(1 / \rho)_{\mathrm{y}}$

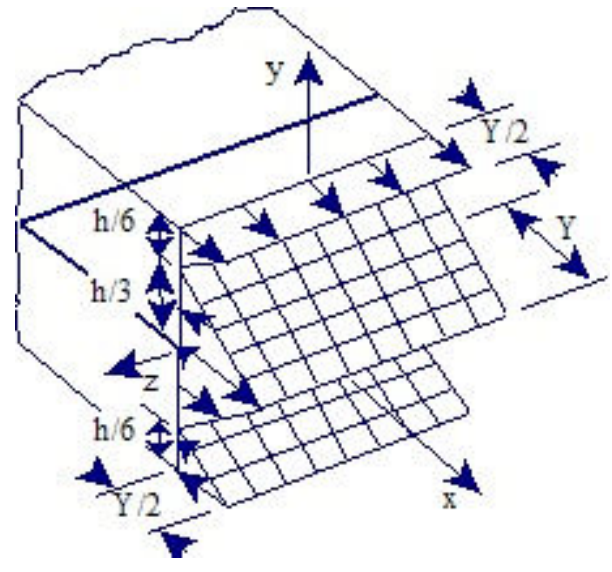

(c) $\quad \mathrm{M}_{\mathrm{b}}=0$

$$
1 / \rho=1 / R_{1}=1 / R_{\mathrm{o}}-3 / 2(1 / \rho)_{\mathrm{y}}
$$

Figure 5. Residual stress distribution in a rectangular bar.

\section{Generation of Surface Residual Stresses from Surface Grinding}

Many research studies have been done on the stresses induced in steels by surface grinding. In any grinding process there are numerous variables which can influence the residual stress in the surface and sublayer of material. Some important ones are the mechanical properties, structure and composition of the metal, the depth of cut in grinding, feed and speed of the grinding wheel, and wheel parameters and coolant used. In the early 1950s, Colwell ${ }^{3}$ studied the effect of 
residual stress induced by grinding hardened 4340 steel. He concluded that the higher the hardness level of the steel, higher values of residual stress was produced in the material. Also, the depth of penetration of the residual stress increased as the austerity of grinding increased. Halverstadt's ${ }^{4}$ research showed that by using lower grinding wheel speeds and feeds with a sulfurized oil coolant, he could minimize the residual stress in the material. In the early 1970s, Malkin ${ }^{5,6}$ studied the thermal effect of grinding in the workpiece. He tried to understand how the structure changes in the material surface and sublayers due to the residual stress. He concluded that 60 percent of the total thermal energy generated in grinding flowed into the workpiece. Yonetani ${ }^{7}$ measured the residual stress in high hardness specimens ground with various conditions. The results of his research show that the magnitude and distribution of residual stress was greatly affected by the volume change due to the tempering of the surface layer material caused by the heat generated in grinding. He also showed that the maximum residual stress and grinding temperature have a linear relation. The linear relationship depends on the hardness of each specimen. Rowe's and Helieby's ${ }^{8}$ research indicates that abusive grinding produces tensile residual stress since the thermal effect becomes dominant. And that gentle grinding generates compressive residual stress due to the mechanical effect. More recently Leskovar ${ }^{9}$ investigated and measured the residual stress on and beneath the surface after rough and fine grinding with different grinding wheels. His results show that grinding with a freshly dressed wheel produces compressive stresses just beneath the surface, but these soon change into extremely high tensile stresses. He also showed that different types of abrasive did not affect the hardness of the surface.

\section{Stress Strain Relationships}

To understand the equations of how residual stress is calculated by $\mathrm{x}$-ray diffraction its is best to start with Hooke's law for elastic materials. Hooke's law states the relationship of stress to strain within an elastic isotropic medium. Employing a cubic element of volume in Figure 6 with a cartesian coordinate system the equations for a triaxial stress system are listed below in terms of their principal axes ${ }^{10}$.

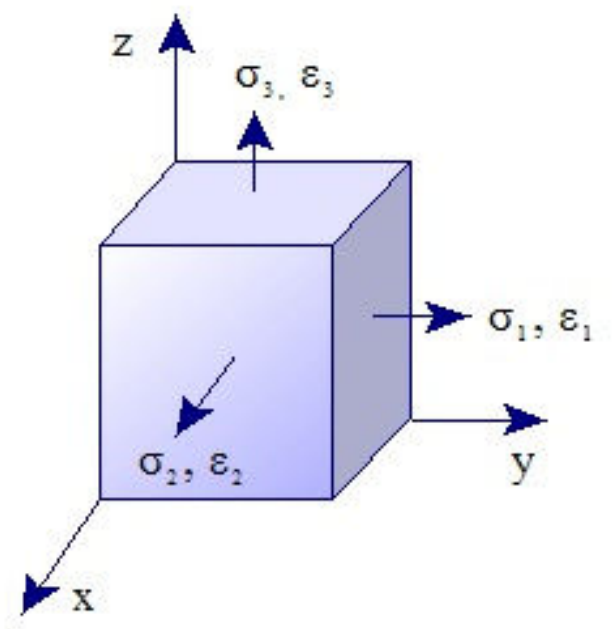

$$
\begin{aligned}
& \varepsilon_{1}=\frac{1}{E}\left[\sigma_{1}-v\left(\sigma_{2}+\sigma_{3}\right)\right] \\
& \varepsilon_{2}=\frac{1}{E}\left[\sigma_{2}-v\left(\sigma_{3}+\sigma_{1}\right)\right] \\
& \varepsilon_{3}=\frac{1}{E}\left[\sigma_{3}-v\left(\sigma_{1}+\sigma_{2}\right)\right]
\end{aligned}
$$

Figure 6. Cubic element volume. 
In a spherical coordinate system in Figure 7 the distortion of a spherical element of volume will be deformed into an ellipsoid. By setting the principal strain and stress axes parallel to a set of orthogonal $\mathrm{x}, \mathrm{y}, \mathrm{z}$ axes the equation for the strain ellipsoid is given by the relation ${ }^{11}$.

$\frac{x^{2}}{\varepsilon_{1}}+\frac{y^{2}}{\varepsilon_{2}}+\frac{z^{2}}{\varepsilon_{3}}=1$

In Figure 6 the strain $\varepsilon_{\varphi \psi}$ is a normal strain vector shown on the ellipsoid plane. This strain vector can be expressed in terms of principal strains $\varepsilon_{1}, \varepsilon_{2}, \varepsilon_{3}$ and direction cosines.

$$
\varepsilon_{\varphi \psi}=\varepsilon_{1} \alpha_{1}^{2}+\varepsilon_{2} \alpha_{2}^{2}+\varepsilon_{3} \alpha_{3}^{2}
$$

Where the direction cosines are defined as:

$$
\begin{aligned}
& \alpha_{1}=\cos \varphi \sin \psi \\
& \alpha_{2}=\sin \varphi \sin \psi \\
& \alpha_{3}=\cos \psi=\left(1-\sin ^{2} \psi\right)^{\frac{1}{2}}
\end{aligned}
$$

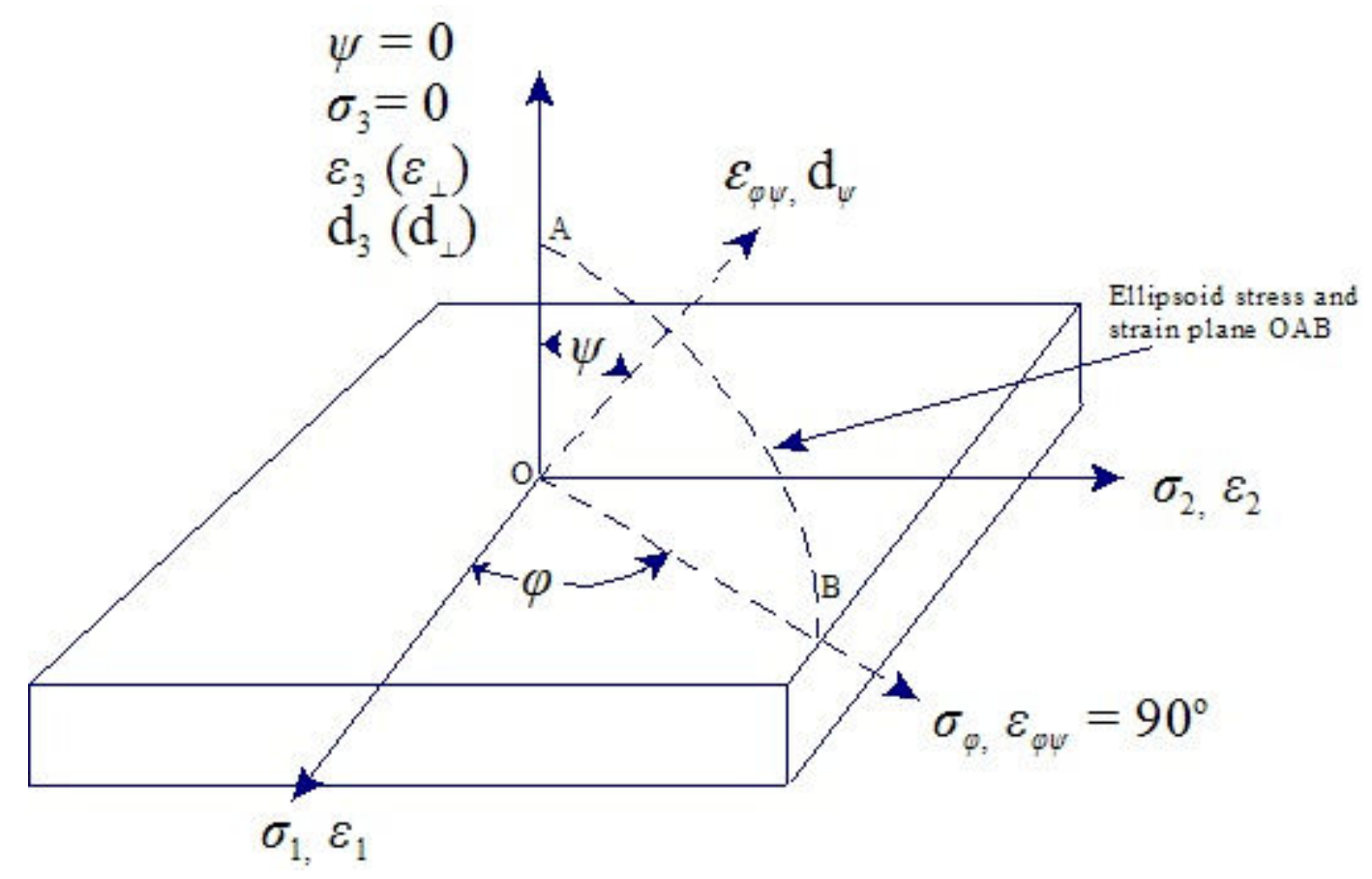

Figure 7. Stress and strain in a spherical coordinate system using units employed in x-ray diffraction stress analysis. 
Similarly the stress $\sigma_{\varphi \psi}$ can also be expressed in terms of principal stresses $\sigma_{1}, \sigma_{2}$, and $\sigma_{3}$.

$$
\sigma_{\varphi \varphi}=\sigma_{1} \alpha_{1}^{2}+\sigma_{2} \alpha_{2}^{2}+\sigma_{3} \alpha_{3}^{2}
$$

By substituting equation 1 into equation 3 the general equation relating stresses to strain using units employed in $\mathrm{x}$-ray diffraction is obtained for any direction $\varphi, \psi$.

$$
\varepsilon_{\varphi \psi}=\frac{1+v}{\mathrm{E}}\left(\sigma_{1} \alpha_{1}^{2}+\sigma_{2} \alpha_{2}^{2}+\sigma_{3} \alpha_{3}^{2}\right)-\frac{v}{\mathrm{E}}\left(\sigma_{1}+\sigma_{2}+\sigma_{3}\right)
$$

At the surface of a specimen the x-ray diffraction measurement is confined to plane stress conditions. This means that there are two principal stresses $\sigma_{1}$ and $\sigma_{2}$ with $\sigma_{3}$ equal to zero. Also, due to Poisson's ratio there will be three non zero principal strains $\varepsilon_{1}, \varepsilon_{2}$, and $\varepsilon_{3}$. These stresses and strains are shown in Figure 8 with $\varepsilon_{3}\left(\varepsilon_{\perp}\right)$ being perpendicular to the $\mathrm{x}$, y plane. Setting $\sigma_{3}$ to zero in equation 6 and substituting in $\alpha_{1}=\cos \varphi \sin \psi$ and $\alpha_{2}=\sin \varphi \sin \psi$ transforms equation 6 to a plane stress condition.

$$
\varepsilon_{\varphi \psi}=\frac{1+\nu}{\mathrm{E}}\left(\sigma_{1} \cos ^{2} \varphi+\sigma_{2} \sin ^{2} \varphi\right) \sin ^{2} \psi-\frac{\nu}{\mathrm{E}}\left(\sigma_{1}+\sigma_{2}\right)
$$

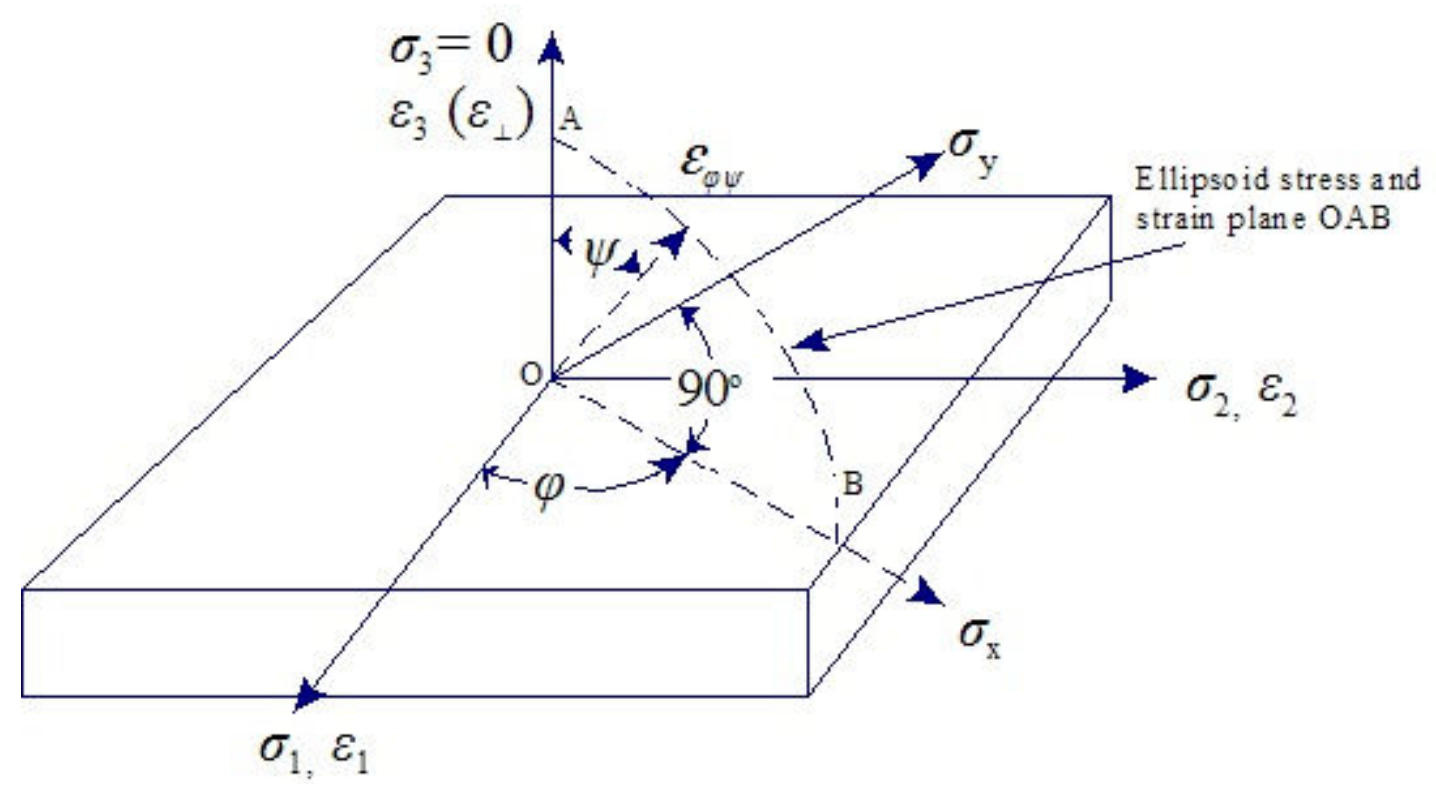

Figure 8. Stress and strain in a biaxial system. 


\section{X-ray Residual Stress Measurement}

$\mathrm{X}$-ray diffraction residual stress measurement is unique in that macroscopic residual stresses can be determined nondestructively ${ }^{12}$. In X-ray diffraction residual stress measurement, the strain is measured in the crystal lattice and the residual stress producing the strain is calculated. This is based on the assumption of the linear elastic theory of solid mechanics. The x-ray diffraction stress measurement is confined to the (hkl) planes on the surface of the material in Figure 9. To determine this stress, the atomic spacing $d$ must be measured in the crystal lattice for at least two precisely known orientations relative to the sample surface as shown in Figure 10. Then a plane stress elastic model can be derived to explain the state of stress.

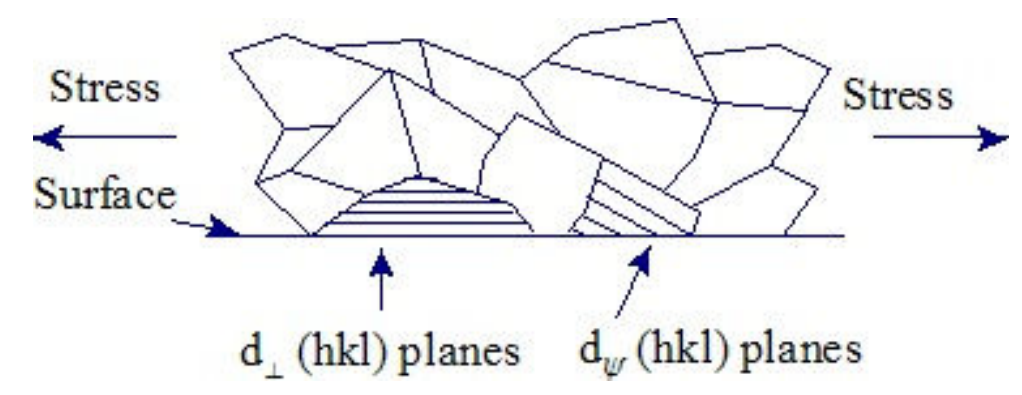

Figure 9. Lattice (hkl) planes shown in grain boundaries for x-ray diffraction.

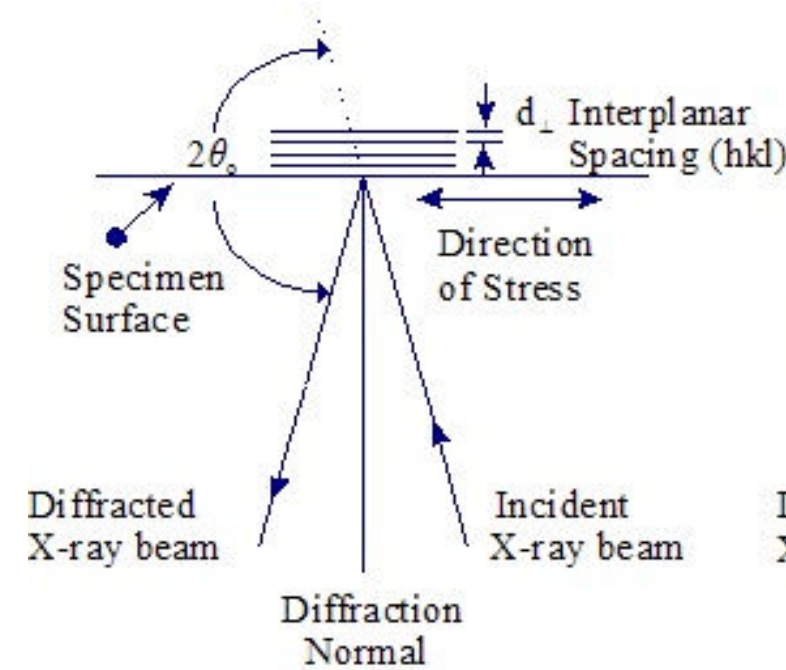

(a) Measuring planes parallel to the surface $\psi=0$

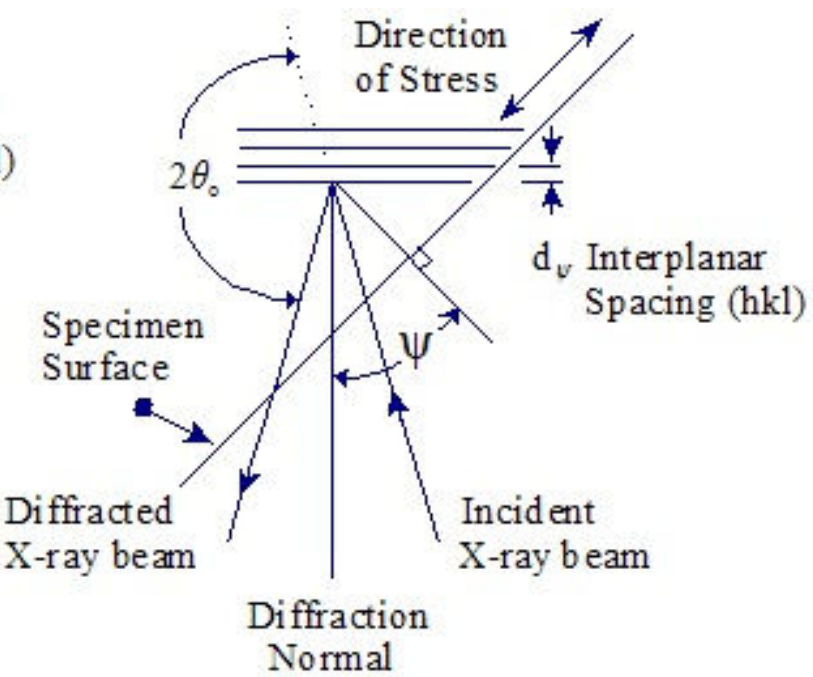

(b) Measuring planes at the angle $\psi$ to the surface

Figure 10. Orientation of measured lattice planes with respect to specimen surface. 
For the direction shown in Figure 10, the strain $\varepsilon_{\varphi \psi}$ can be calculated from the following equation which was derived in the previous section.

$$
\varepsilon_{\varphi \psi}=\frac{1+v}{E}\left(\sigma_{1} \cos ^{2} \varphi+\sigma_{2} \sin ^{2} \varphi\right) \sin ^{2} \psi-\frac{v}{E}\left(\sigma_{1}+\sigma_{2}\right)
$$

Strain $\varepsilon_{\varphi \psi}$ is also calculated from atomic plane spacing (hkl) show below.

$$
\varepsilon_{\rho \psi}=\frac{\mathrm{d}_{\psi}-\mathrm{d}_{0}}{\mathrm{~d}_{\rho}}
$$

The value of $d_{o}$ represents the unstressed lattice spacing. However, to measure $d_{o}$ creates a problem because $d_{0}$ must be measured on a small stress free section cut out of the specimen. By doing this the procedure becomes a destructive measurement technique. Therefore, by using the approximation that $\mathrm{d}_{\mathrm{o}} \cong \mathrm{d}_{\perp}$ and substituting into equation 8 , the error in the strain value is negligible. Therefore the state of stress can be calculated without knowing the stress free atomic plane spacing $d_{o}$. By substituting equation 10 into 6 yields equation 11 .

$$
\begin{aligned}
& \varepsilon_{o v}=\frac{d_{v}-d_{\perp}}{d_{\perp}} \\
& \sigma_{\phi}=\sigma_{1} \cos ^{2} \varphi+\sigma_{2} \sin ^{2} \varphi \\
& \varepsilon_{\phi \varphi}=\frac{1+v}{E} \sigma_{\varphi} \sin ^{2} \psi-\frac{v}{E}\left(\sigma_{1}+\sigma_{2}\right)
\end{aligned}
$$

Equation 11 relates the lattice strains to stresses, and can be utilized to determine the surface stress $\sigma_{\varphi}$ in any direction.

\section{Stress Equation as a Function of $\operatorname{Sin}^{2} \psi$}

The $\sin ^{2} \psi$ technique is generally used as a standard method for accurately measuring residual stress. It has the advantage that it uses the linear relationship between $\varepsilon_{\varphi \psi}$ and $\sin ^{2} \psi$ in equation 11. The technique utilizes a diffractometer to measure lattice strains by recording high angle diffraction lines generated by the x-ray. The diffraction of these x-rays from the crystal lattice will occur when Braggs law is fulfilled ${ }^{13}$.

$n \lambda=2 \mathrm{~d} \sin \theta$

where $n$ is an interger, $\lambda$ is the wavelength of the $\mathrm{x}$-ray beam, $\mathrm{d}$ is the atomic plane spacing and $2 \theta$ is the diffraction angle. The $\sin ^{2} \psi$ procedure involves the measurement of several values of 
lattice strains corresponding to successive equal interval values of $\sin ^{2} \psi$. A plot of lattice strain versus $\sin ^{2} \psi$ is shown in Figure 11. The slope $M$ is represented by differentiating equation 11 with respect to $\sin ^{2} \psi$.

$\mathrm{M}=\frac{\partial \varepsilon_{\phi \psi}}{\partial \sin ^{2} \psi}=\frac{1+v}{\mathrm{E}} \sigma_{\varphi}$

By preforming a least square regression analysis with the data collected calculates the slope of lattice strain as a function of $\sin ^{2} \psi$. This leads directly to the stress $\sigma_{\varphi}$ expressed as

$$
\sigma_{\varphi}=\frac{\mathrm{ME}}{v+1}
$$

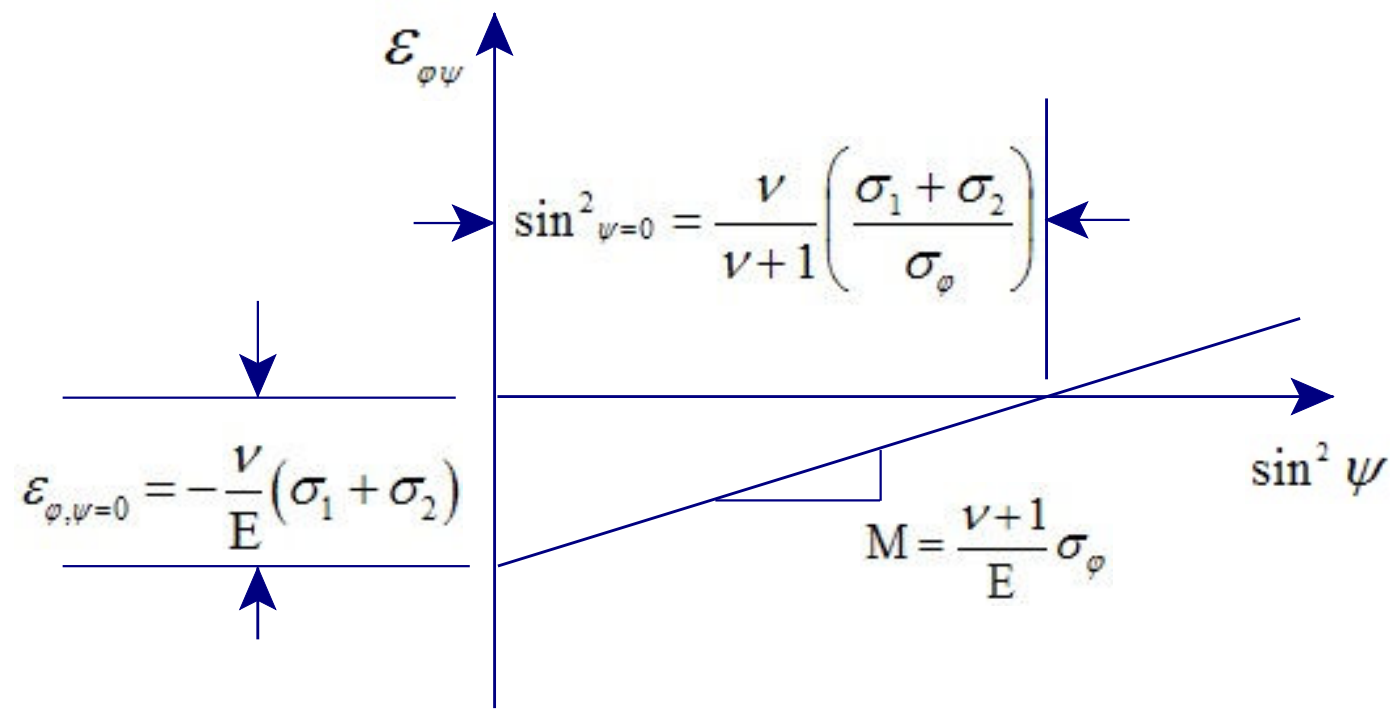

Figure 11. Graph of the $\sin ^{2} \psi$ method with $\varphi$ equal to a constant.

\section{Residual Stress Measurement Procedure}

To measure residual stress, a specimen must be mounted in a x-ray diffraction fixture. In this paper the $\sin ^{2} \psi$ method was discussed as the most common technique used. Diffraction measurements are made with the specimen oriented at angles of $\psi=0^{\circ}$ (normal to surface), $30^{\circ}$, $45^{\circ}$ and $60^{\circ}$. The corresponding spacial plane displacement $d$ is calculated by the shift in the Bragg angle $2 \theta$. Values of strain are calculated by equation 9 and a linear regression plot of $\boldsymbol{\varepsilon}_{\varphi \psi}$ versus $\sin ^{2} \psi$ is created with $\varphi$ equal to a constant. The slope of the graph is determined and by utilizing equation 14 the stress in the $\varphi$ direction is known. To determine the principal stresses and their direction this procedure is repeated for three different angles of $\varphi$. Assuming a plane stress condition on the surface the principal stresses along with their directions can be calculated by implementing Mohr's circle. 


\section{Sources of Error}

As with any measurement system that collects data there are usually some errors that may occur. In $\mathrm{x}$-ray diffraction these errors can be generated from the following sources.

1. Due to material anisotropy the $\mathrm{x}$-ray elastic constants $\frac{E}{1+v}$ may vary up to $40 \%$ compared to bulk values.

2. Course grain materials and rough surface finishes cannot be measured reliably. Course grain has too few crystals and rough surfaces contribute to $\mathrm{x}$-ray displacement errors.

3. Specimen alignment and instrumental alignment generally has to be within .001 in. At .001 in the error in stress is approximately 2 ksi.

\section{Effect of Residual Stresses on Surface Integrity and Fatigue}

Each year, the U.S. spends approximately 50 billion dollars in producing mechanical components by chip removal processes. The service life of a machine part is significantly affected by the surface integrity generated by its manufacturing processes. Most of the research done in this area is empirical and directed toward the practical solution of particular machining problems. There is only a little knowledge about the mechanisms which control the integrity of the surface and its sublayers.

The integrity of a surface generally can be defined by its metallurgical, mechanical, chemical, and topological states. This paper will mainly deal with the mechanical and topological state of the surface and its sublayers. Studies of machine surfaces produced by cutting, pertaining to residual stress and hardness variation started in the early 1950s. Kakino and Okushima ${ }^{14}$ investigated the effect of heat generated by the cutting process, and the mechanical deformation of the cutting surface on residual stresses. They used a finite element analysis to show how the residual stress was produced. But in their final analysis they could not conclude what percentage of residual stress was produced by thermal expansion or by the plowing force of the cutting tool. Research done by Metcut Associates ${ }^{15}$ indicates that there is no agreement either on the parameters which describe the mechanical state of a machined surface or on the machining parameters which govern it. There have been many contradictory interpretations that are unexplainable by the knowledge available in this area. They concluded that more research was needed in this area to correlate and confirm how different machining operations affect the surface integrity. Work-hardening in the sublayer was investigated by Camatini ${ }^{16}$ in the 1970s. He used micro hardness measurements to show that the depth of hardening in the steel increased with the carbon content.

More recently Liu and Barash ${ }^{17,18}$ showed that the maximum residual stress and strain hardening index are approximately proportional to the shear plane length for a given depth of cut. They also found that the mechanical state of the sublayer of a surface generated by chip removal process is determined by the shear plane length, flankwear and depth of cut. In machining hardened 4340 steel, Jeelani and Baily ${ }^{19}$ studied the effect of cutting speed and tool wear length 
in orthogonal cutting conditions. They found that cutting at low speeds formed a wide variety of geometrical defects on the surface. This was generated from the discontinuous chip formation. At high cutting speed most of the damage occurs primarily in the form of metallurgical changes associated with the subsurface. They concluded that this was caused by the high temperatures generated between the tool nose region and workpiece. The effects of grinding and other machining processes of hardened steel were investigated by Tarasov and Grover $^{20}$. Their results showed that the fatigue strength of surfaces where microcracks are present is much lower than the fatigue strength of the interior subsurface metal. And the yield strength of metals measured after fatigue loading was much lower than the yield strength as measured by static tests. More recently, Field and Koster ${ }^{21}$ stated that as the strength level of high strength steels increases, fatigue and stress corrosion resistance become more sensitive to surface integrity produced by machining.

Helieby and Rowe $\mathrm{e}^{22}$ investigated the influences of residual stress and surface roughness on the fatigue life of ground EN31 steel. They concluded that in grinding the effect of residual stresses was more dominant in determining the fatigue strength of the steel than the surface roughness. Macheranch and Scholtes ${ }^{23}$ studied the effect of surface roughness, surface hardening and residual stress on the fatigue strength of medium carbon steel created by different heat-treatment and machining conditions. They showed that the influence of macro residual compressive stress increased the fatigue limit, and the increase in the hardness of the surface and sublayer of the material also increased the fatigue strength.

Surface topography and residual stress was investigated by Leverant and Langer ${ }^{24}$ on the fatigue strength of T1-6A1-4V alloy. Their analysis concluded that surface residual stresses play a key role in the determination of fatigue microcrack growth rates and total fatigue life. They also confirmed that the sharpness of machining grooves more than their depth is an additional factor that influences fatigue properties. The crack opening behavior under the influence of surface residual stress was investigated by Hack and Chan ${ }^{25}$. They modeled the crack opening using a three dimensional boundary integral analysis. Their prediction showed excellent agreement with observed behavior for a corner crack in T1-6A1-4V specimens with and without the presence of compressive surface residual stresses. They observed that the presence of compressive surface residual stress severely restricts the opening of the crack. Gray and Wagner ${ }^{26}$ investigated the effect of residual stress on fatigue crack propagation in the shot peened specimens of Ti-6A1-4V. Their results show that at room temperature, compressive residual stresses decrease the propagation rate of small microcracks. At elevated temperatures, residual stress tends to relax and crack propagation is enhanced due to the presence of a high dislocation density in the surface structure. The influence of residual stress produced by machining on the bending fatigue strength of AISI 1045 steel was investigated by Hoffman and Lohe ${ }^{27}$. They showed that surface residual stresses produced by milling normalized 1045 steel were small. And that compressive surface residual stresses produced by grinding have little effect on the bending fatigue strength, because the affected depth is rather shallow.

It is accepted that ceramics are being used more frequently in the machine tool industry. They have the ability to be used as a finishing tool to replace secondary machining operations in soft and hard-to-machine materials. The surface integrity of a machined part clearly affects its performance. The residual stresses produced by machining increase or decrease fatigue life 
mainly by preventing, delaying or accelerating the growth of cracks. Crack nucleation consists of small tubular holes that are in persistent slip bands and twin boundaries. Commercial alloy material introduces segregation, inclusions and second phase particles that disturb the structure. All of these have a significant influence on the crack nucleation process and the total fatigue life of the material.

\section{Conclusion}

There are many parameters created by manufacturing processes that affect a machine part performance and its overall life. This paper looked at the effect of machining and manufacturing processes relating to surface integrity and fatigue life. In particularly single point cutting and grinding of machine components. These are very common machining practices that are used to produce engineering parts and components. Parameters closely investigated are the generation of residual stresses by these manufacturing processes. It was shown that these residual stresses can be calculated by strength of material equations and the theory of elasticity. However, it requires experimental strain measurements of atomic plane spacing $\mathrm{d}$ and the use of the Bragg's equation $n \lambda=2 \mathrm{~d} \sin \theta$.

In x-ray diffraction the x-rays are diffracted off the atoms and remain in phase as long as the lattice spacing $d$ is a constant. When a mechanical or residual stress is present the lattice spacing $\mathrm{d}$ changes. This change results in a shift of the Bragg angle $2 \theta$. By measuring this angle shift the lattice spacing $d$ is calculated. With the data collected the $\sin ^{2} \psi$ technique is used to calculate the stress in the $\varphi$ direction.

Engineering students should be aware that their designs assumes a stress free state on the surface of the material. Actually there can be tensile or compressive stresses present depending how the part was manufactured. There isn't a textbook that students can look up residual stress values for different manufacturing conditions. There is only empirical data in the literature from researchers outlined in this paper. In general compressive residual surface stresses are beneficial to surface integrity. These stresses add vectorially to mechanical stresses and restrict crack nucleation for the time dependent failure mode of fatigue. As compare to tensile residual stresses which accelerate the crack nucleation process and reduces fatigue life.

\section{Bibliography}

1. Trent, E.M., "Forces in Metal Cutting," Metal Cutting, 2nd. ed., Butterworths, London, 1984, pp. 34-48.

2. Cook, R.D. and Young, W.C., "Stress, Strain, Energy and Failure," Advanced Mechanics of Materials, 1st ed., Macmillan, New York, 1985, pp. 1-39.

3. Colwell, L.V. and Sinnott, M.J., and Tobin, J.C., "The Determination of Residual Stresses in Hardened Ground Steel," Journal of the American Society of Mechanical Engineers, Vol. 77 Ap., 1955, pp. 354.

4. Halverstadt, R.D., "Analysis of Residual Stress in Ground Surfaces of High-Temperature Alloys," American Society of Mechanical Engineers Transactions, Vol. 80, May, 1958, pp. 929-940. 
5. Malkin, S. and Anderson, R.B., "Thermal Aspects of Grinding," Journal of Engineering for Industry, Vol. 96, No. 4, Nov 1974, pp 1177-1183.

6. Malkin, S., "Surface Temperatures and Workpiece Burn," Journal of Engineering for Industry, Vol. 96, No. 4, Nov. 1974, pp. 1184-1197.

7. Yonetani, S. and Notoya, H., "Grinding Residual Stress in Heat Treated High Hardness Steels," Journal of Japan Institute of Metals, June 1984.

8. EL-Helieby, S.O. and Rowe, G.W., "Influence of Surface Roughness and Residual Stress on Fatigue Life of Ground Steel Components," Metals Technology, Vol. 7, June, 1980, pp. 221-225.

9. Leskovar, P., "Investigations of Surface Integrity of Workpieces and Tools," Strojniski Vestnik, Sept-Oct 1985.

10. Timoshenko, S.P. and Goodier, J.N., "Theory of Elasticity", $3^{\text {rd }}$ edition, McGraw-Hill Book Company, 1951.

11. American Society for Metals Handbook, Materials Characterization, Vol. 10, X-Ray Diffraction Residual Stress Techniques, pp. 380-392, Fifth printing 1998.

12. Residual Stress Measurement by X-Ray Diffraction SAEJ784a, Society of Automotive Engineers, Inc., New York, New York, 1971.

13. Cullity, B.D., "Measurement of Residual Stress," Elements of X- Ray Diffraction, 2nd ed., Addison-Wesley, Massachusetts, 1978, pp. 447-476.

14. Okushima, K. and Kakino, Y., "A Study on the Residual Stress Produced by Metal Cutting." Memoir of Faculty of Engineering Kyoto University Vol. 34, No. 2, April, 1972.

15. Koster W.P., "Surface Integrity of Machined Structural Components Interim," Report No IR-721-8I Metcut Res. Assoc, 1968.

16. Camatini, E., "A Systematic Research on the Cold Work Produced on Carbon Steels by Machining with a Lathe," Proc 8th Int. M.T.D.R. Conference, Manchester, 1967.

17. Liu, C.R. and Barash, M.M., "The Mechanical State of the Sublayer of a Surface Generated by Chip-Removal Process," Journal of Engineering for Industry, Vol. 98. No. 4, Nov. 1976, pp. 1192-1201.

18. Liu, C.R. and Barash, M.M., "Cutting With a Tool With Flank Wear," Journal of Engineering for Industry, Vol. 98, No. 4, Nov., 1976, pp. 1202-1208.

19. Bailey, J.A., Jeelani, S., and Becker, S.E., "Surface Integrity in Machining AISI 4340 Steel," Journal of Engineering for Industry, Vol. 98, No. 3, Aug., 1976, pp. 999-1007.

20. Tarasov, L.P. and Grover, H.J., "Effects of Grinding and Other Finishing Processes on the Fatigue Strength of Hardened Steel," American Society for Testing Materials Vol. 50, ASTM Philadelphia 1950, pp. 668-698.

21. Koster, W.P. and Field, M., "Machining of High Strength Steels With Emphasis on Surface Integrity," Technical Rept. 70, p 276, Rept. no. A.F.M.D.C.-70-1 Metcut Research Assoc.

22. Helieby, S.O.A. and Rowe, G.W., "A Quantitative Comparison Between Residual Stresses and Fatigue Properties of Surface-Ground Bearing Steel," Wear Magazine, Vol. 58, 1980, pg. 155.

23. Macherauch, E. and Scholtes, B., "Recent Applications of XSA in Heat Treatment and Fatigue of Steels," Advances in X-ray Analysis, Vol. 27, Plenum Press, New York, 1983, pp. 179-190. 
24. Leverant, G.R. and Langer, B.S., "Surface Residual Stresses, Surface Topography and the Fatigue Behavior of T1-6A1-4V," Metallurgical Transactions, Vol. 10A, No. 2, Feb., 1979, pp 251-257.

25. Hack, J.E., Chan, K.S., and Cardinal, J.W., "The Prediction of the Crack Opening Behavior of Part-through Fatigue Cracks Under the Influence of Surface Residual Stresses," Engineering Fracture Mechanics, Vol. 21, No. 1, Mar., 1985, pp. 75-84.

26. Gray, H. and Wagner, G., "Influence of Residual Stresses on Fatigue Crack Propagation of Small Surface Cracks," Residual Stresses in Science and Technology, Vol. 2, 1987, pp. 815-822.

27. Hoffman, D., Lohe, E. and Macherauch, E. "Influence of Machining Residual Stresses on the Bending Fatigue Behavior of Notched Specimens of Ck45 in Different Heat Treating States," Residual Stresses in Science and Technology Vol. 2, 1987, pp. 801-808. 